\title{
Political Polarization and the Electoral Effects of Media Bias
}

\author{
Dan Bernhardt
}

\author{
Stefan Krasa
}

March 20, 2006

\author{
Mattias Polborn*
}

\begin{abstract}
Many political commentators diagnose an increasing polarization of the U.S. electorate into two opposing camps. However, in standard spatial voting models, changes in the political preference distribution are irrelevant as long as the position of the median voter does not change. We show that media bias provides a mechanism through which political polarization can affect electoral outcomes.

In our model, media firms' profits depend on their audience rating. Maximizing profits may involve catering to a partisan audience by slanting the news. While voters are rational, understand the nature of the news suppression bias and update appropriately, important information may be lost through bias, resulting in inefficient electoral outcomes. We show that polarization increases the profitability of slanting news, thereby raising the likelihood of electoral mistakes.
\end{abstract}

JEL Classification Numbers: C70, D72.

Keywords: Media bias, polarization, information aggregation, democracy.

*Address of the authors: Department of Economics, University of Illinois, 1206 South 6th Street, Champaign, IL 61820 USA, E-mails: danber@uiuc.edu, skrasa@uiuc.edu, polborn@uiuc.edu.

Dan Bernhardt gratefully acknowledges financial support from NSF grant SES-0317700. Stefan Krasa gratefully acknowledges financial support from NSF grant SES-0318394. 


\section{Introduction}

Several recent books argue that most major media outlets in the U.S. report the news with a severe bias. Depending on the author's political stance, the deplored bias is either to the left (Goldberg (2003), Coulter (2003)) or to the right (Alterman (2003), Franken (2003)). Media bias is often blamed for the fact that voters' beliefs on key policy issues are sometimes blatantly false. For example, as Table 1 indicates, a large percentage of the U.S. population had mistaken beliefs about facts surrounding the Iraq war. Most strikingly, these beliefs differed substantially between liberals and conservatives, indicating that these groups receive information from different sources, and that some of these sources bias the news by suppressing or deemphasizing certain events that could be perceived as unfavorable by their respective audiences.

Table 1: Harris Opinion Poll, October 21, 2005

\begin{tabular}{||l|c|c|c||}
\hline \hline & Total & $\begin{array}{c}\text { Bush } \\
\text { supporters }\end{array}$ & $\begin{array}{c}\text { Kerry } \\
\text { supporters }\end{array}$ \\
\hline Saddam Hussein had strong links to Al-Qaeda & $62 \%$ & $84 \%$ & $37 \%$ \\
Saddam Hussein helped plan and support the hijackers who & $41 \%$ & $52 \%$ & $23 \%$ \\
attacked the US on September 11, 2001 & $38 \%$ & $58 \%$ & $16 \%$ \\
\hline Iraq had weapons of mass destruction when the US invaded & $38 \%$ \\
\hline \hline
\end{tabular}

Relatedly, many political commentators diagnose a sharp and increasing partisan divide that splits the U.S. electorate. For example, the Economist writes that "the 50-50 nation appears to be made up of two big, separate voting blocks, with only a small number of swing voters in the middle", ${ }_{1}^{1}$ and that "America is more bitterly divided than it has been for a generation". ${ }^{2}$ In contrast, Fiorina, Abrams, and Pope (2004) argue that even though partisans may be more partisan, there is a large center of voters who are largely ambivalent or indifferent and that "there is little evidence that Americans' ideological or policy positions are more polarized today then they were two or three decades ago, although their choices often seem to be."

We develop a model in which an increase in partisan behavior is not due to a fundamental change of voter's political preferences, but rather due to media bias. This media bias arises endogenously as an optimal choice by profit-maximizing media in response to (some) voters' preferences. Media bias manifests itself as suppression of information. While voters know that media are biased and update rationally, they cannot completely recover the suppressed information. We address the questions of whether and when media bias causes a failure of information aggregation in elections. Even though some voters will have mistaken beliefs, it is far from obvious that the wrong electoral outcomes will occur. For example, as documented by an extensive literature rooted in the Condorcet Jury Theorem, democracies can achieve perfect information aggregation, even when the quality of information of individual voters is poor (see, for example, Feddersen and Pesendorfer (1996)).

We identify the conditions under which this suppression of news leads to electoral failures. We show that media are more likely to be biased when some citizens are more partisan. We then show how the

\footnotetext{
1“'On His High Horse," Economist, November 9, 2002: 25.

2“America's Angry Election,” Economist, January 3, 2004.
} 
suppression of information by the media can affect preference intensities so that even moderates look like partisans. Because the endogenous media bias depends on the distribution of citizen preferences, electoral outcomes depend not only on the location of the median voter, but also on the entire distribution.

To understand how this endogenous suppression of information can lead to electoral failure, consider the following example. Suppose there are both conservative and liberal media outlets, each presenting only the negative news about the opposing candidate. Applied to the the 2004 U.S. Presidential Elections, the liberal outlet would have focused on the lack of those weapons of mass destruction that provided the rationale of the Bush administration for the Iraq war, while a conservative outlet would have emphasized Kerry's "flip-flopping," illustrated by the widely-quoted line by Kerry: "I voted for the 84 Billion before I voted against it." In our model, voters are rational and understand that their news sources are biased. Thus, even though a listener to the conservative news source remains uninformed about the lack of WMDs in Iraq, he understands that there may be some news that was not reported. If the realized negative news about Kerry's "flip-flopping" is more important than the unobserved (expected) negative news about Bush, then even very moderate listeners of the conservative outlet vote for Bush. Similarly, all listeners to the liberal outlet vote for Kerry, as long as the news about the missing WMDs is more important than the expected, but unobserved, weakness of Kerry. In this instance, the conservative candidate is elected if and only if the median voter listens to the conservative outlet, and his election is inefficient if and only if under complete information this voter would have considered the WMD issue to dominate the character issue.

The fundamental source of possible electoral inefficiency is a problem of failing to internalize positive externalities. While all or most voters would benefit from a better-informed electorate, each individual citizen has virtually no influence on the electoral outcome. As a consequence, the value of news for an individual citizen is primarily given by its entertainment value, and not by its informational value. Depending on preferences, the consumption value of news may be higher for biased than for unbiased news. Specifically, while more moderate liberals and conservatives prefer unbiased news, stronger partisans in both camps may favor news consistent with their ideological predisposition. Our modeling assumptions correspond to the observation of Posner (2005): "So why do people consume news and opinion? [...] They want to be entertained, and they find scandals, violence, crime, the foibles of celebrities and the antics of the powerful all mightily entertaining. And they want to be confirmed in their beliefs by seeing them echoed and elaborated by more articulate, authoritative and prestigious voices. So they accept, and many relish, a partisan press."

Because the preference of citizens for confirmatory news is more pronounced for stronger partisans, if partisans are not too extreme, media outlets compete by providing unbiased news. In contrast, in society with extreme partisans, it can be profitable for media to gear the news to one side of the political spectrum. Thus, the desire of partisans to receive confirmatory news reinforces the externality problem so that political polarization can alter electoral outcomes.

Our paper is related to three distinct literatures. One literature analyzes whether democratic election aggregating information efficiently. Wittman (1989) argues that democracy leads to efficient outcomes as long as voters do not make systematic mistakes. ${ }^{3}$ In his view, elections would be unaffected by media bias

\footnotetext{
${ }^{3}$ Wittman (2005) expands on this argument, noting that if the only voters who mistakenly believed that Iraq had weapons of mass destruction and was behind 9/11, were those voters who would have voted for Bush anyway, then media bias was irrelevant for the electoral outcome, and hence irrelevant from an efficiency perspective.
} 
when voter are rational. Feddersen and Pesendorfer (1996) and Feddersen and Pesendorfer (1997) consider a common value model in which voters receive stochastically-independent information about the state of the world. They show that information aggregation in large electorates is asymptotically efficient. Martinelli (2004) endogenizes voters' decisions about how much information to acquire. If marginal information acquisition costs are initially zero, then efficient outcomes arise despite the public good provision problem. In contrast to these models, in our paper all citizens listening to the same outlet receive the same information. Even though each individual citizen in our model receives more complete information than in the above models, all listeners to the same media outlet receive the same information. Thus, no law of large numbers result for perfect information aggregation applies to our model.

There is an emerging literature that investigates the sources of media bias (Mullainathan and Shleifer (2005), Baron (2004), Gentzkow and Shapiro (2005)). As in our model, Mullainathan and Shleifer (2005) assume that media bias is caused by preference for confirmatory news. However, in their paper the bias can be undone by rational agents. Hence, we cannot use their approach for our analysis. In Baron (2004) bias can arise because journalists have a preference for providing news that is in line with their own political views. Gentzkow and Shapiro (2005) introduce a model in which media firms care about their reputation for accurately reporting news. Interestingly, when the true state of the world is not always revealed ex-post, this reputational concern may discourage media from reporting their information truthfully and, instead, induce them to provide confirmatory news.

In our model, we assume that media can selectively omit relevant information that conflicts with their viewers' beliefs and preferences, but they cannot "fabricate" news outright. Groseclose and Milyo (2005) argue that news suppression is by far the more important form of media bias: "Cases such as Jayson Blair, Stephen Glass, or the falsified memo at CBS are rare; they make headlines when they do occur; and much of the time, they are orthogonal to any political bias. Instead, for every sin of commission, such as those by Glass or Blair, we believe that there are hundreds and maybe thousands of sins of omission - cases where a journalist chose facts or stories that only one side of the political spectrum is likely to mention." For example, the (conservative) Media Research Center reported on June 24, 2005 that for several days the main U.S. networks did not report on the controversy following Senator Durbin's Guantanamo-Gulag speech, news that was widely perceived as damaging for Durbin and the Democratic party.

Our primary goal is to determine the electoral effects of media bias. Our preference-based approach to modeling media bias provides a credible and tractable framework that we can use as a primitive for investigating electoral effects. However, even if media bias is due to other reasons (as in Gentzkow and Shapiro (2005) or Baron (2004)), the electoral effects that we find would still apply, as long as media bias leads to a loss of information that cannot be fully recovered by voters.

Finally, our paper contributes to the spatial theory of elections, pioneered by Downs (1957). ${ }^{4}$ The central result of this literature is the median voter theorem, which shows that solely the location of the median voter determines the electoral outcome - the distribution of voters and the polarization of the electorate are irrelevant. In contrast, the distribution of political preferences matters in our model, because it influences the optimal behavior of media and hence the information of the electorate.

\footnotetext{
${ }^{4}$ For a review of this literature, see Osborne (1995).
} 


\section{The Model}

Players and Time Structure. There are 2 news media outlets, 2 candidates for a office, and a continuum of measure one of citizens. A citizen's political preferences are given by $\theta=\tau+\rho$, where $\tau$ is the realization of the median voter (distributed according to $\operatorname{cdf} G$ ), and $\rho$ is the voter's deviation from the median (distributed according to cdf $F$ ). We assume that $F$ and $G$ have differentiable symmetric density functions $f$ and $g$, respectively, and that both distributions have mean zero. The density function describing the ex-ante distribution of $\theta$ is therefore $h(\theta)=\int f(\theta-\tau) g(\tau) d \tau$. We say that a voter $\theta<0$ is liberal while a voter $\theta>0$ is conservative. Each citizen knows his type $\theta$, but does not know either $\rho$ or $\tau$. Hence a citizen does not know whether or not he is decisive in the election, and the probability of being pivotal is zero.

There are two candidates $i=L, R$ running for office. Candidate $i$ 's type is characterized by $\left(x_{i}, q_{i}\right)$, where $x_{i}$ is a policy position, and $q_{i} \in \mathbb{R}$ is the candidate's valence-valence is a quality such as integrity or ability that all citizens appreciate in a politician. We assume that policy positions are symmetric around 0 , so that $0<x_{R}=-x_{L}$. Citizens cannot directly observe the valence $q_{i}$. Media outlets are completely informed about the candidates' valences, which they can — possibly incompletely — report to their listeners. ${ }^{5}$ Let $Y_{i}^{+}$and $Y_{i}^{-}$be the random variables that describe positive and negative news, respectively about candidate $i$, and let $y_{i}^{+}$and $y_{i}^{-}$be the associated realizations. ${ }^{6}$ Candidate $i$ 's valence is then given by $q_{i}=y_{i}^{+}-y_{i}^{-}$. We assume that the cdfs of $Y_{i}^{+}$and $Y_{i}^{-}$are continuous. To simplify the exposition we assume that $E\left[Y_{L}^{+}+Y_{R}^{-}\right]=$ $E\left[Y_{L}^{-}+Y_{R}^{+}\right]$, i.e., the candidates have the same ex-ante expected valence.

The game extends over three stages.

Stage 1 The media outlets announce reporting strategies, specifying for every possible vector of news realizations, the set of stories that they will report. Formally, an action by media outlet $i$ in stage 1 is given by a function $\zeta_{i}: \mathbb{R}_{+}^{4} \rightarrow\{0,1\}^{4}$, where 0 indicates that the news is suppressed, while 1 indicates that the news is reported. For example, $\zeta_{i}\left(y_{L}^{+}, y_{L}^{-}, y_{R}^{+}, y_{R}^{-}\right)=(0,1,1,0)$ indicates that for this particular realization, media outlet $i$ reports only the negative news about the left candidate and the positive news about the right candidate.

Stage 2 Each citizen $\theta$ chooses an outlet $i$ to which he listens and a listening time $t \geq 0$.

Stage 3 After Bayesian updating about $q_{i}$, citizens vote for their preferred candidate.

Citizens' preferences. Citizens receive utility from listening to the news and from the electoral outcome. In principle, citizens might listen to news in order to make a better-informed electoral choice; however, since the probability to be pivotal in the election is (essentially) zero for each individual voter, this incentive is very small in large electorates. Rather, we assume that citizens listen to the news as a consumption good: Some news is just interesting or entertaining for citizens, and this provides sufficient motivation for citizens to listen to the news for some time. In this respect, we assume that citizens, ceteris paribus, prefer to hear

\footnotetext{
${ }^{5}$ The assumption that the media are completely informed about the candidates' valences may appear to be a strong one, but should only be understood as the media initially having more information about valence than voters. The objective of the model is to analyze whether the media transmit their additionally available information efficiently.

${ }^{6}$ We show below that the restriction to one item of positive and negative news about each candidate is without loss of generality.
} 
news that is positive for their ideologically-closer candidate and negative about the opposing candidate. It helps to define $\eta\left(y_{L}^{+}, y_{L}^{-}, y_{R}^{+}, y_{R}^{-}\right)=\left(-y_{L}^{+}, y_{L}^{-}, y_{R}^{+},-y_{R}^{-}\right)$, where favorable news about candidate $R$ and unfavorable news about candidate $L$ enter $\eta$ positively, while unfavorable news about $R$ and favorable news about $L$ enter negatively. Citizen $\theta$ 's "listening" utility in stage 2 is given by

$$
u_{\theta}^{2}(t, y, \zeta, i)=\left[\gamma+\alpha \theta \zeta_{i}(y) \cdot \eta(y)+\beta \zeta_{i}(y) \cdot y\right] t-0.5 t^{2},
$$

where $\alpha, \beta, \gamma>0$, and "." denotes the inner product of vectors. ${ }^{7}$ The parameter $\beta$ captures a citizen's preference for "bigger" news stories, and $\alpha|\theta|$ captures citizen $\theta$ 's preference for positive stories about his preferred candidate and negative stories about his opponent. Hence, a strong partisan with $\alpha|\theta|>\beta$ prefers to listen to news biased in favor of his candidate, and against his opponent, while moderates $(\theta \approx 0)$ prefer to receive all news. Finally, $\gamma>0$ captures the enjoyment derived from listening to aspects of the news show that are distinct from the political news stories themselves-sports, weather, entertainment, world and domestic news.

We assume that each citizen only listens to a single outlet for his news. While listening to several outlets could, in principle, lead to better information, the zero probability of being pivotal implies that listening to both outlets is generically not optimal if outlets use different reporting strategies (i.e., except perhaps for the one type who is indifferent between the outlets). If outlets use the same reporting strategy, then whether a citizen listens to one or both outlets is irrelevant for his information. Hence, our assumption that citizens listen to only one outlet is effectively without loss of generality.

Citizen $\theta$ 's utility in stage 3 when candidate $e$ is elected is

$$
u_{\theta}^{3}\left(q^{1}, q^{2}, e, v\right)=-\left(\theta-x_{e}\right)^{2}+\kappa q^{e},
$$

where $\kappa>0$ captures the weight in citizen preferences on valence relative to ideology. Citizen $\theta$ 's total utility reflects both his listening enjoyment and the electoral outcome, and is the weighted sum of (1) and (2),

$$
u_{\theta}^{2}(t, y, \zeta, i)+\lambda u_{\theta}^{3}\left(q^{1}, q^{2}, e, v\right)
$$

where $\lambda>0$ determines the importance of the election relative to the consumption of news programs.

Media Profits. We assume that a media outlet makes its profits from advertising. Advertising profits are proportional to the time citizens spend listening to outlet $j$. In particular, if $T_{j}=\int t_{j}^{*}(\theta) h(\theta) d \theta$ is the aggregate listening time by $j$ 's audience, then $j$ 's profits are equal to

$$
\Pi_{j}(T)=\pi T_{j}-\mathrm{FC}
$$

where $\pi>0$ is the marginal profit and FC are the media outlet's fixed operating costs.

\footnotetext{
${ }^{7}$ For example, if media outlet $i$ reports only negative news about $L$ and positive news about $R$, then $\zeta_{i}(y)=(0,1,1,0)$ and $\theta$ 's utility is $\left[\gamma+\alpha \theta\left(y_{L}^{-}+y_{R}^{+}\right)+\beta\left(y_{L}^{-}+y_{R}^{+}\right)\right] t-0.5 t^{2}$. If, instead, $\theta$ listens to an outlet $j$ that reports all news, i.e., $\zeta_{j}(y)=(1,1,1,1)$, then $\theta$ 's utility is $\left[\gamma+\alpha \theta\left(-y_{L}^{+}+y_{L}^{-}+y_{R}^{+}-y_{R}^{-}\right)+\beta\left(y_{L}^{+}+y_{L}^{-}+y_{R}^{+}+y_{R}^{-}\right)\right] t-0.5 t^{2}$.
} 


\section{Equilibrium Analysis}

\subsection{Equilibrium in the media market}

Suppose that citizen $\theta$ listens to outlet $j$, which has a reporting strategy $\zeta_{j}$. Citizen $\theta$ chooses his listening time to maximize expected utility, (1). The quadratic structure of preferences implies that if the optimal listening time is positive, it is given by

$$
t=E\left[\gamma+\alpha \theta \zeta_{i}(Y) \cdot \eta(Y)+\beta \zeta_{i}(Y) \cdot Y\right]=\gamma+\alpha \theta E\left[\zeta_{i}(Y) \cdot \eta(Y)\right]+\beta E\left[\zeta_{i}(Y) \cdot Y\right] .
$$

Thus, only the expected news enters the decision about how long to listen to a particular media outlet, as the listener only learns the actual news after the fact. While the actual news matters for a citizen's Bayesian updating, it is sufficient to focus on the expected news in order to determine the equilibrium in the media market. Furthermore, (5) indicates that only the net news about each candidate matters, which is the positive news about the candidate himself plus the negative news about his opponent. Formally define

$$
Z_{L}=Y_{L}^{+}+Y_{R}^{-}, Z_{R}=Y_{R}^{+}+Y_{L}^{-} \text {, and } \bar{z}=E\left[Z_{R}\right]=E\left[Z_{L}\right]
$$

Then by an appropriate choice of a reporting strategy $\zeta$, a media outlet can achieve any arbitrary expected net reported news $0 \leq s_{L} \leq \bar{z}$ and $0 \leq s_{R} \leq \bar{z}$. (Formally, $s_{L}=E\left[\zeta(Y) \cdot\left(Y_{L}^{+}, 0,0, Y_{R}^{-}\right)\right]$and $s_{R}=$ $\left.E\left[\zeta(Y) \cdot\left(0, Y_{L}^{-}, Y_{R}^{+}, 0\right)\right].\right)$ The resulting listening time is then

$$
t=\gamma+\alpha \theta\left(s_{R}-s_{L}\right)+\beta\left(s_{R}+s_{L}\right) .
$$

Note that an outlet would never simultaneously suppress both net news that favors the liberal candidate and net news that favors the conservative. To see why, suppose by contradiction that positive news about both candidates is suppressed, so that $s_{L}<\bar{z}$ and $s_{R}<\bar{z}$. If a media outlet increases both $s_{L}$ and $s_{R}$ by the same amount, then the second term on the right-hand side of (7) does not change, while the third term increases. Thus, listening time and media profits would increase, a contradiction. We now state the result formally.

Lemma 1 In any equilibrium, each media outlet reports at least all positive news about one candidate and all negative news about his opponent, i.e., $\zeta(Y)=(1, a(Y), b(Y), 1)$ or $\zeta(Y)=(a(Y), 1,1, b(Y))$ for all $Y$, where $a(Y), b(Y): Y \rightarrow\{0,1\}$.

Lemma 1 indicates that each media outlet fully reports the net news about at least one candidate. It still allows for the possibility of partial news suppression about the opposing candidate. In Proposition 1, we show that this is not the case, if the distribution of citizens has the following property:

Condition $1 h^{\prime}(\theta) \geq-\frac{\alpha}{\beta} h(\theta)$, for all $\theta \in(0, \beta / \alpha)$.

Condition 1 stipulates that the density function does not drop off too rapidly for moderate citizens who are close to the center of the distribution. For example, if $h$ is normally distributed with mean 0 and standard deviation $\sigma$ then Condition 1 is satisfied if $\sigma>\frac{\beta}{\alpha}$. To interpret this condition, note that $\frac{\beta}{\alpha}$ and $-\frac{\beta}{\alpha}$ separates 
moderates who prefer unbiased news from partisans. Applied to normal distributions, Condition 1 is satisfied as long as all moderates are within one standard deviation of the expected mean, i.e., there are not more than about $68 \%$ moderates. However, we note that the condition is sufficient but far from necessary. Numerical analysis indicates that the result of Proposition 1 holds for all normal distributions.

Proposition 1 If Condition 1 holds, then in equilibrium, each media outlet chooses one of three reporting strategies: "unbiased reporting", $\zeta(Y)=(1,1,1,1)$ for all $Y$; "reporting biased to the left", $\zeta(Y)=$ $(1,0,0,1)$ for all $Y$; or "reporting biased to the right", $\zeta(Y)=(0,1,1,0)$ for all $Y .{ }^{8}$

We know from Lemma 1 that each media outlet reports all net positive information for at least one candidate. We then use Condition 1 to show that media outlet's payoff is convex in the net news reported about the opposing candidate. As a consequence, the optimum is at a corner where all the net news is either reported or suppressed. Because convexity is not a necessary condition for a corner solution, the result of Proposition 1 holds more generally.

Under the conditions of Proposition 1, media outlets are either unbiased or completely biased. It may seem that, in reality, bias on many TV channels is less stark, as even channels that are considered to be ideologically biased often have shows that attract viewers from the opposite side of the political spectrum. However, the relevant level of competition for our questions is not the entire set of broadcasts, but rather competition between individual shows. For example, MSNBC broadcasts the "Countdown" for more liberal viewers, followed by "Scarborough Country," which targets conservatives. Similarly, Fox News Sunday, with its panel of four conservatives and one liberal appeals to a more Republican audience, while the immediately following program, "The Chris Matthews Shows", has a far more liberal panel. One can certainly not conclude from this that channels target a centrist audience, because few viewers of one program stick around for the other. ${ }^{9}$ Rather, the channels find it more profitable to target different partisan audiences at different time slots. Thus, in practice, a biased-biased equilibrium should be interpreted as a situation in which the vast majority of broadcasts target partisan audience, instead of the political center.

We next characterize equilibria. From Proposition 1, a media outlet is either unbiased, left biased, or right biased. While this gives rise to six possible configurations, asymmetric equilibria in which both outlets are biased to the left or both outlets are biased to the right do not arise because of the symmetric distribution of voters. For example, if the competing media outlet has a left bias, it is more profitable to choose an opposing bias to the right than the same left bias. This leaves the following possible equilibrium configurations.

Proposition 2 For a given $\beta, \gamma$ and distribution $H(\cdot)$, we can partition the set of bias preference parameters $\alpha$ into three non-empty regions: a low-bias region $\left(0, \alpha_{1}\right)$, a medium-bias region $\left(\alpha_{1}, \alpha_{2}\right)$, and a high-bias region $\left(\alpha_{2}, \infty\right)$, where

\section{Both an unbiased-unbiased and unbiased-biased equilibria exist for $\alpha$ in the low-bias region.}

\footnotetext{
${ }^{8}$ It should be noted that this result extends to an arbitrary number of media outlets.

${ }^{9}$ Indeed, the moderator of Fox News Sunday usually forgoes inviting viewers to watch the upcoming Chris Matthews Show on the same channel, a highly unusual behavior on American TV.
} 


\section{Only an unbiased-biased equilibrium exists in the medium-bias region.}

3. Only a biased-biased equilibrium exists in the high-bias region.

$\alpha_{1}$ solves

$$
\frac{1}{2}[\gamma+2 \beta \bar{z}]=\left(1-H\left(\frac{\beta}{\alpha_{1}}\right)\right)\left[\gamma+\left(\alpha_{1} E_{\Theta}\left[\Theta \mid \Theta \geq \frac{\beta}{\alpha_{1}}\right]+\beta\right) \bar{z}\right],
$$

and $\alpha_{2}$ solves

$$
\frac{1}{2}\left[\gamma+\left(\alpha_{2} E_{\Theta}[\Theta \mid \Theta \geq 0]+\beta\right) \bar{z}\right]=H\left(\frac{\beta}{\alpha_{2}}\right)[\gamma+2 \beta \bar{z}] .
$$

Central to the proof of Proposition 2 is the identity of the listener $\hat{\theta}$, who is indifferent between the two news outlets. If one outlet has a left bias and the other has a right bias then the marginal listener is $\hat{\theta}=0$. If, instead, one news outlet is biased, say to the right, while the other outlet is unbiased, then listener $\theta=0$ strictly prefers the unbiased outlet to the biased outlet, and the same is true for those right-of-center moderates with $\theta<\hat{\theta}=\frac{\beta}{\alpha}$.

To understand equation (8), note that the right-hand side is the payoff to an outlet that switches from being unbiased to being biased (say to the right). The average listening time is given by $E\left[\gamma+\alpha \theta Z_{R}+\right.$ $\beta Z_{R} \mid \theta>\frac{\beta}{\alpha}$ ], because only conservatives $\theta>\frac{\beta}{\alpha}$ listen to the right-biased outlet. To understand the left-hand side of equation (8), note that the total listening time of two unbiased outlets together is $E\left[\gamma+\alpha \theta\left(Z_{R}-\right.\right.$ $\left.\left.Z_{L}\right)+\beta\left(Z_{R}+Z_{L}\right)\right]$. Since $E\left[Z_{R}\right]=E\left[Z_{L}\right]=\bar{z}$, total media profit is therefore $\gamma+2 \beta \bar{z}$. Furthermore, it is easiest to support an equilibrium with unbiased outlets if listeners split equally, which accounts for the coefficient of $1 / 2$. In the proof we show that the right-hand side of equation (8) increases faster than the lefthand side when $\alpha$ increases. Thus, unbiased equilibria can be supported if and only if $\alpha \leq \alpha_{1}$. Otherwise, if $\alpha>\alpha_{1}$ it is optimal for any of the outlets to deviate to biased reporting.

The left-hand side of equation (9) is the ex-ante payoff of a media outlet if both outlets are biased. If both are biased, they must be biased in opposite direction. Thus, all liberals $\theta<0$ listen to the liberal outlet, while all conservatives $\theta>0$ listen to the conservative outlet, so that each outlet expects $50 \%$ of the citizens as listeners. Apart from the different set of listeners, the expression is the same as the right-hand side of (8). Now suppose the previously-liberal outlet becomes unbiased, so that all citizens $\theta<\frac{\beta}{\alpha}$ tune in. Its ex-ante expected payoff corresponds to the left-hand side of (8), with the factor $1 / 2$ replaced by $F\left(\frac{\beta}{\alpha}\right)$. We show in the appendix that the left-hand side of (9) increases faster than the right-hand side as $\alpha$ increases. Thus, for $\alpha>\alpha_{2}$ it is optimal for both outlets to be biased, while for $\alpha<\alpha_{2}$ it is optimal for at least one outlet to report unbiased news, and a biased-biased equilibrium cannot be supported.

It is interesting to note that the existence of the intermediate region with only a biased-unbiased equilibrium implies that media bias is a strategic substitute for outlets and not a strategic complement. That is, suppose that both outlets are initially unbiased, but parameters change such that one of them finds it just profitable to introduce a bias. Then it is not optimal for the other outlet to become biased as well. The argument is related to that above. When one outlet becomes biased, say to the left, then it loses all left-of-center moderates, thereby increasing both the profit of the remaining unbiased outlet and, more importantly, its incentive to provide unbiased news-as it now caters to all moderate listeners.

We next show that increasing polarization increases the incentive to provide biased broadcasts targeting partisans. To do this we first define what it means for a society to become more politically polarized. More 
political polarization simply means that there are fewer citizens in the center and more in the extremes.

Definition 1 Let $H(\theta)$ and $\hat{H}(\theta)$ be cdfs for two different symmetric distributions of citizens. Then the society described by $\hat{H}$ is more polarized than the society described by $H$ if and only if $H(\theta) \leq \hat{H}(\theta)$ for all $-\infty<\theta<0$ where the inequality is strict for some $\theta<-\frac{\beta}{\alpha}$.

When a society becomes more polarized, the cutoffs $\alpha_{1}$ and $\alpha_{2}$ described in Proposition 2 decrease, because it becomes more profitable for media outlets to cater to partisans. If a media outlet remains unbiased, the increase in polarization does not affect its overall listening time (i.e., the rating of the program). In contrast, a biased outlet is rewarded by an increase in listening time of their partisan viewers. Consequently, as polarization increases, media outlets find it more profitable to replace balanced discussions by one-sided presentations. For example, the show "Capital Gang" on CNN, with a balanced roundtable was discontinued, presumably due to a lack of viewership.

Proposition 3 Suppose that a society described by $\hat{H}$ is more polarized than that by $H$. Then both $\alpha_{1}$ and $\alpha_{2}$ are strictly smaller under $\hat{H}$.

Proposition 3 reveals that partisan polarization affects the composition of news reporting. This, in turn, influences the information of the citizens, which then may impact the electoral outcome. Thus, in contrast to almost all results in the spatial theory of voting, we show that not only the location of the median voter (or the distribution over the location of the median), but also the whole distribution, in particular the polarization of the electorate, matters.

\subsection{Electoral Consequences of Media Bias}

We now determine how media bias affects electoral outcomes, and under what conditions media bias results in electoral inefficiencies. Because citizens in our model are completely rational and understand the nature of the biases, they update appropriately and then vote for the candidate whom they prefer given their information. Hence, even citizens who listen to biased media do not make systematic mistakes regarding the valence of their ideologically-preferred candidate and his opponent. However, because information is incomplete due to bias, the wrong candidate may get elected.

We define the ex-post efficient choice as the candidate whose election maximizes aggregate social welfare. Note that our definition of ex-post efficiency is utilitarian, because Pareto optimality alone has no bite in our model.

Definition 2 Given the realization $\tau$ of the median voter, and the valences $q_{i}, i=L, R$, candidate $i$ is the electorally efficient choice if and only if $-\int\left(\tau+\theta-x_{i}\right)^{2} f(\theta) d \theta+\kappa q_{i} \geq-\int\left(\tau+\theta-x_{j}\right)^{2} f(\theta) d \theta+\kappa q_{j}$.

Due to the symmetry in the distribution of voters, this utilitarian definition is equivalent to to the following:

Lemma 2 Candidate $i$ is the ex-post efficient choice if and only if voter $\tau$ prefers candidate i, i.e., $-(\tau-$ $\left.x_{i}\right)^{2}+\kappa q_{i} \geq-\left(\tau-x_{j}\right)^{2}+\kappa q_{j}$. 
The following three propositions provide a complete classification of all situations in which ex-post inefficiencies occur. Because of the symmetry of our results, we restrict attention to the case where the conservative candidate's realized net news is lower than that of his liberal opponent. We can subdivide the set of voters into intervals of voters of different degrees of moderation. Whether or not inefficiencies arise depends on the location of the median voter $\tau$ with respect to these intervals.

First, as noted in Section 2, voters in $|\theta|<\frac{\beta}{\alpha}$ prefer to receive all news, even news that is negative about their preferred candidate. We refer to such voters as moderates. In contrast, more partisan liberals or conservative have $|\theta|>\frac{\beta}{\alpha}$, and prefer one-sided presentations. For example, if the news is discussed by a roundtable of experts, then a moderate would prefer an evenly-split panel that provides different perspectives on an issue, while, for example, a more partisan conservative prefers a more one-sided panel (such as Fox News Sunday).

Proposition 4 considers the case where the realized net news about both candidates exceeds the expected net news, $\bar{z}$, identifying when electoral inefficiencies occur. Recall that the net news about candidate $i$ consists of the positive news $y_{i}^{+}$about $i$ and the negative news $y_{j}^{-}$about his opponent. The net news about a candidate can be above average when either he has very good news about himself, or when his opponent has skeletons in his closet. For example, if there is very good and very bad news about the same candidate, then the resulting net news for both candidates can be above average. Polborn and Yi (2006) argue that the negative news in election campaigns is typically more important, because the level of possible positive news about a candidate is limited compared to the possible downsides of scandals. If so, the case $z_{L}, z_{R}>\bar{z}$ may be generated more frequently by significant negative revelations about both candidates.

Proposition 4 Suppose that $z_{L}>z_{R}>\bar{z}$. Then ex-post inefficiencies occur if and only if one of the following two conditions holds.

1. Both outlets are biased and the median voter is conservative with $0<\tau<\frac{\kappa\left(z_{L}-z_{R}\right)}{4 x_{R}}$.

2. There is an unbiased outlet, an outlet that is biased to the right, and the median voter is conservative with $\frac{\beta}{\alpha}<\tau<\frac{\kappa\left(z_{L}-z_{R}\right)}{4 x_{R}}$.

The expected utility gain of a listener to a biased outlet from his preferred candidate is bounded away from zero. Moreover, marginal changes in news do not affect the voting behavior of citizens who listen to biased news outlets.

Proposition 4 indicates that there are two ways in which the wrong candidate may be elected. The first case applies to a sufficiently polarized society such that both media outlets are biased (see Proposition 3 ). If the median voter is slightly conservative and listens to a right-biased outlet then he only observes $z_{R}$ but not $z_{L}$. As a consequence, given that $z_{L}$ exceeds the expected net news $\bar{z}$ of a liberal candidate, our voter concludes that candidate $R$ is the better choice. However, when the true net news is $z_{L}>z_{R}$, a voter who is moderately conservative, i.e., $0<\tau<\frac{\kappa\left(z_{L}-z_{R}\right)}{4 x_{R}}$ would prefer candidate $L$, if fully informed. The cutoff reflects the relative weight $\kappa$ on valence and the policy divergence captured by $x_{R}$. For example, the median voter may be primarily informed about scandals involving the liberal candidate, and not sufficiently informed about the even larger problems affecting the conservative candidate. In the resulting equilibrium, 
all citizens vote along party lines. Moreover, marginal changes in news have absolutely no effect on vote shares, because citizens' expected utility gain from their preferred candidate is bounded away from zero. Thus, the net difference between $z_{L}$ and $z_{R}$ determines whether a mistake occurs.

Case 2 considers a somewhat less polarized society, where a biased-unbiased equilibrium exists. Here, mistakes are less likely because all moderates listen to the unbiased outlet. For a mistake to occur, the median voter must be quite conservative and the net news difference must be large enough that the median voter would switch to the liberal candidate if he were correctly informed about the problems of the conservative candidate. Finally, if there is very little polarization, all media outlets are unbiased and no mistakes are made.

Proposition 4 shows that not only the location of the median voter, but also the political polarization influences electoral outcomes. With lower political polarization, voters are better informed and many moderates cross over to vote for the other party's candidate. In contrast, with more polarization voters may lack the information to make such choices. As a consequence, an increase in the number of strong partisans on both sides results in moderates also voting along party lines.

We now summarize key facts about recent U.S. presidential elections and relate them to our results above. In the 2004 U.S. Presidential election, negative news about both candidates was substantial. Liberal media emphasized the run up to the war in Iraq, while conservative news programs emphasized Kerry's uncertain character. According to Case 1 of Proposition 4, the electorate should appear strongly divided, with liberals and conservatives having strong preference intensities for their respective candidates. Moreover, the perceived preference polarization would be based on the different information that voters received, rather than on an increased polarization of the underlying political preferences. Specifically, we argue the following:

1. The distribution of ideologies ( $\theta$ in our model) has remained stable over the past few decades. The fact that people appear more polarized in some recent elections therefore must be caused by some other factor.

2. In the 2004 election, Bush and Kerry supporters held vastly different beliefs about facts influenced by the media, relative to their differences in core beliefs (e.g., abortion), which are less influenced by media.

3. Voters held stronger preferences over candidates in the 2004 presidential election than in the 2000 election.

Stability of the ideological preference distribution. Many political commentators argue that the U.S. electorate is far more polarized today than ever (see, for example, Dan Balz's article in the Washington Post, on March 29, 2005 and the citations from the Economist in the introduction).

However, comparing the Gallup polls taken in the weeks before the 2000 and 2004 elections reveals that the percentages of citizens who classified themselves as either very conservative, conservative, moderate, liberal, or very liberal changed only marginally. Similarly, the number of registered voters who do not identify themselves as Democrats or Republicans has not changed since 1997 (Pew Research Report, 
http://people-press.org/reports/display.php3?ReportID=196). More generally, Fiorina, Abrams, and Pope (2004) argues that the alleged increased political polarization is a myth and shows through the analysis of numerous surveys and opinion polls that the distribution of political preferences in the U.S. has not changed fundamentally in the last few decades.

Our model of media bias and its electoral effects provides a framework that can reconcile the tension between these two conflicting views: Different and biased information that the two camps of voters receive may sometimes create the appearance of a more polarized electorate even though the underlying preference distribution did not change.

Table 2: Exit Polls, 2004 US Elections

\begin{tabular}{||c|c|c||}
\hline \hline & Bush & Kerry \\
\hline Is Iraq part of the war on terrorism & & \\
Yes 55\% & $81 \%$ & $18 \%$ \\
No 42\% & $11 \%$ & $88 \%$ \\
\hline How are things going for the U.S. in Iraq & & \\
well 44\% & $90 \%$ & $9 \%$ \\
badly 52\% & $17 \%$ & $82 \%$ \\
\hline Abortion should be ... & & \\
mostly or always legal 55\% & $33 \%$ & $67 \%$ \\
mostly or always illegal 42\% & $75 \%$ & $24 \%$ \\
\hline \hline
\end{tabular}

Different beliefs about facts. Exit polls taken after the 2004 U.S. presidential election reveal that Bush and Kerry supporters disagreed dramatically about facts relevant for the election (see the first two entries of Table 2). Consider, for example, the question of whether things were going well in Iraq. In principle, the answer to this question is factual, and if all citizens had listened to truly unbiased news reporting, there should be significant consensus among voters in both camps. However, while roughly $50 \%$ of voters thought the war was going well, the electorate split on this question almost exactly along party lines. A person who believed that things were going well for the U.S. in Iraq was ten times more likely to vote for Bush than for Kerry.

A very plausible interpretation consistent with our model is that liberals and conservatives received information from sources with different biases. A study by the Project for Excellence in Journalism assessing the tone of Iraq war coverage in different news cable news channels supports this view. The study found that Fox was "distinctly more positive than negative. Fully $38 \%$ of Fox segments were overwhelmingly positive in tone, more than double the $14 \%$ of segments that were negative. [...] On CNN, in contrast, $41 \%$ of stories were neutral in tone on the 20 days studied, and positive and negative stories were almost equally likely $-20 \%$ positive, $23 \%$ negative."

One could still suspect that the reason for the split along party lines in the question on Iraq is that 
voters split along party lines on all major policy issues, whether or not media bias is an issue. However, the responses on contentious hot-button issues such as abortion or the role of civil liberties show that this is not the case. For example, the question whether or not abortion should be legal, is a worse predictor of voting intentions than the first two, presumably factual, questions in Table 2. In particular, the 2004 exit polls indicate that a voter who wanted abortion to be mostly or always illegal, was only three times as likely to be a Bush supporter. ${ }^{10}$ Similarly, $43 \%$ of Republicans and 55\% of Democrats indicated in August 2003 that is not necessary to curb civil liberties to fight terror, and $66 \%$ of Republicans and $82 \%$ of Democrats agreed that we should pay less attention to problems overseas (Pew Research Report). Our interpretation is that preferences about these issues are less directly affected by news reporting, suggesting that news media were responsible for the apparent polarization of the electorate.

Increased preference intensity in 2004. The Gallup polls taken before the election ask to what degree a respondent supports a candidate. For the 2004 elections they find stronger preferences than in the previous three presidential elections. In particular, for the 2004 elections, $71 \%$ of voters indicated a strong preference for their candidate. In contrast, the number is $64 \%$ for the 2000 elections, ${ }^{11}$ and the numbers were even lower in previous elections. Given that partisans are likely to support their candidate strongly in any election, these numbers indicate that significantly more moderates had strong preferences in the 2004 elections. Stronger preference intensities by moderates correspond to a smaller percentage of undecided voters. The exit polls of the 2000 and 2004 elections support this claim. In 2004, only $11 \%$ of voters were undecided until the last week, while the corresponding number for 2000 was $18 \%$. Similarly, the corresponding percentages for being undecided a month before the elections were $22 \%$ in 2004 and $31 \%$ in 2000 .

Higher preference intensity should also generate a high voter turnout if we endogenize participation. ${ }^{12}$ Consistent with this view, $64 \%$ of all citizens 18 -year old and above voted in the 2004 election, compared to $58 \%$ and $60 \%$, respectively, in 1996 and 2000 .

The next proposition considers the case where the liberal candidate's net news is above average, while the conservative candidate's is below average. Fixing the positive news about each candidate near the expected value, this would be the case if there are few problems with the liberal candidate, while the conservative candidate is involved in scandals.

Proposition 5 Suppose that $z_{L}>\bar{z}>z_{R}$. Then ex-post inefficiencies occur if and only if one of the following two conditions holds.

1. Both outlets are biased and the median voter is a conservative with $\frac{\kappa\left(\bar{z}-z_{R}\right)}{4 x_{R}}<\tau<\frac{\kappa\left(z_{L}-z_{R}\right)}{4 x_{R}}$.

2. There is an unbiased outlet, an outlet that is biased to the right, and the median voter is a conservative with $\tau>\beta / \alpha$ and $\frac{\kappa\left(\bar{z}-z_{R}\right)}{4 x_{R}}<\tau<\frac{\kappa\left(z_{L}-z_{R}\right)}{4 x_{R}}$.

\footnotetext{
${ }^{10}$ Fiorina, Abrams, and Pope (2004) notes that the differences in views on abortion of Republicans versus Democrats would be even lower if we considered all citizens rather than actual voters, because a higher percentage of partisans goes to the polls.

${ }^{11}$ This number is an average of the three polls that asked this question, weighted by number of respondents.

${ }^{12}$ For example, applied to a costly voting model (see Ledyard (1984), Börgers (2004), Krasa and Polborn (2005)), the increased payoff difference would increase turnout.
} 
Moreover, a marginal increase of $z_{R}$ affects the voting behavior of some citizens who listen to biased news outlets, whereas marginal changes of $z_{L}$ do not.

The cases in which inefficiencies occur are qualitatively similar to those of Proposition 4, but mistakes are less likely, as listeners to the right-biased outlet conclude that the liberal candidate has a higher expected valence.

In case 1, where both outlets are biased, some moderate conservatives cross over to the liberal candidate. Mistakes can only occur if the median voter $\tau$ should, but fails to, cross over. All moderates, $\theta<\frac{\kappa\left(\bar{z}-z_{R}\right)}{4 x_{R}}$ cross over because they expect the liberal candidate's valence to be $\bar{z}$. However, because the true valence is $z_{L}>\bar{z}$, it would be optimal for all agents $\theta<\frac{\kappa\left(z_{L}-z_{R}\right)}{4 x_{R}}$ to vote for the liberal candidate. In case 2, mistakes are even less likely because all moderates receive news from an unbiased outlet. Hence, in addition to the conditions of case 1 , the median voter $\tau$ must also be a conservative partisan.

Finally, we consider the case where the net news about both candidates is below average. For example, this would occur if the possible impact of negative news exceeds that of positive news, and the realized bad news about both candidates is limited.

Proposition 6 Suppose that $\bar{z}>z_{L}>z_{R}$. The election result is ex-post inefficient if and only if one of the following occurs.

Case 1 Voter $\tau$ would be better off with candidate $R$, but candidate $L$ wins. This happens if and only if one of the following conditions hold:

1. Both outlets are biased, the median voter is a conservative with $\frac{\kappa\left(z_{L}-z_{R}\right)}{4 x_{R}}<\tau<\frac{\kappa\left(\bar{z}-z_{R}\right)}{4 x_{R}}$, and there are sufficiently many very liberal and moderately conservative voters: $F\left(-\frac{\kappa\left(\bar{z}-z_{L}\right)}{4 x_{R}}-\tau\right)+$ $F\left(\frac{\kappa\left(\bar{z}-z_{R}\right)}{4 x_{R}}-\tau\right)-F(-\tau)>0.5$.

2. There is an unbiased outlet and an outlet that is biased to the right, and the median voter is conservative with $\frac{\beta}{\alpha}<\frac{\kappa\left(z_{L}-z_{R}\right)}{4 x_{R}}<\tau<\frac{\kappa\left(\bar{z}-z_{R}\right)}{4 x_{R}}$, or the following two conditions hold simultaneously: $\frac{\kappa\left(z_{L}-z_{R}\right)}{4 x_{R}}<\frac{\beta}{\alpha}<\tau<\frac{\kappa\left(\bar{z}-z_{R}\right)}{4 x_{R}}$ and $F\left(\frac{\kappa\left(z_{L}-z_{R}\right)}{4 x_{R}}-\tau\right)+F\left(\frac{\kappa\left(\bar{z}-z_{R}\right)}{4 x_{R}}-\tau\right)-F\left(\frac{\beta}{\alpha}-\tau\right)>0.5$.

Case 2 Voter $\tau$ would be better off with candidate L, but candidate $R$ wins. This happens if and only if one of the following conditions hold:

1. Both outlets are biased, the median voter is slightly liberal or conservative with $-\frac{\kappa\left(\bar{z}-z_{L}\right)}{4 x_{R}}<\tau<$ $\frac{\kappa\left(z_{L}-z_{R}\right)}{4 x_{R}}$, and there are sufficiently many very conservative voters and sufficiently many slightly liberal voters: $F\left(-\frac{\kappa\left(\bar{z}-z_{L}\right)}{4 x_{R}}-\tau\right)+F\left(\frac{\kappa\left(\bar{z}-z_{R}\right)}{4 x_{R}}-\tau\right)-F(-\tau)<0.5$.

2. There is an unbiased outlet, an outlet that is biased to the left, the median voter is liberal with $-\frac{\kappa\left(\bar{z}-z_{L}\right)}{4 x_{R}}<\tau<-\frac{\beta}{\alpha}$, and there are sufficiently many moderately liberal voters: $F\left(\frac{\kappa\left(\bar{z}-z_{L}\right)}{4 x_{R}}-\tau\right)+$ $F\left(\frac{\kappa\left(z_{L}-z_{R}\right)}{4 x_{R}}-\tau\right)-F\left(\frac{\beta}{\alpha}-\tau\right)<0.5$.

Moreover, marginal changes of $z_{L}$ and $z_{R}$ always affect vote shares. 
The results of Proposition 6 are qualitatively different from those of Propositions 4 and 5. First, biased information now affects voting behavior for supporters of the candidate with the better net news, i.e., the liberal candidate in our parametrization. The reason is that liberals hear very little bad news about the conservative candidate, and may therefore be tempted to cross over. However, from a social perspective too many liberals may cross over, because they do not know that their own candidate's negative news, which they suspect is being suppressed by the media, is actually insignificant. For the same reason too many conservatives cross over as well. The fact that the liberal candidate is better than the conservative candidate does not guarantee that more conservatives than liberals cross over, so that mistakes can occur.

In Case 1, from the median voter $\tau$ 's perspective, the valence difference between the two candidates is smaller than his preference for the ideologically-closer candidate. However, the liberal candidate wins because more conservatives cross over to vote for the liberal candidate than vice versa. In Case 2, from $\tau$ 's perspective, the valence difference exceeds his ideological preference, but the better candidate loses.

Again, properties of the distribution other than the median influence the electoral outcome. However, in contrast to the cases discussed in Propositions 4 and 5, we now see a more fluid center in which moderates cross party lines. An outside political observer may conclude that the candidates have similar valences, and that voters cross over because they are not inspired by their own candidate.

We can interpret the 2000 U.S. Presidential election, where negative news about both candidates was not very significant, in the context of Proposition 6. In such a scenario, we would expect significant cross-over voting. Following Proposition 4 we have already provided evidence for lower preference intensities and later decision making in the 2000 elections, which suggests that citizens were more likely to cross over. The prediction of Proposition 6 also matches the empirical observation of Della Vigna and Kaplan (2005), who analyze whether the cable channel Fox News influenced voter behavior in the 2000 U.S. presidential election, using variations in the introduction of that channel in different communities. They find that the effect of Fox News on the vote share of the Republican candidate was very small in absolute value and possibly negative. However, a negative effect of Fox News is consistent with our model in the context of Proposition 6.

This shows that a simplistic view of media bias (i.e., voters are not rational and are easily influenced by biased media) is inconsistent with the data. However, their result should also not be interpreted in the sense that media bias never matters for rational voters that take bias into account when updating about candidates. Effectively, one cannot do inference from a single observation, i.e. a single pair of candidates. Our model indicates that media bias matters in general, even though there will be some elections in which it does not. Whether an electoral mistake occurs in a given election, and the nature of the mistake, depends on the information that the media can reveal about the candidates and the ideological distribution of the electorate.

\subsection{Platform Choice}

In our model, a candidate's platform is exogenous. We now discuss how electoral outcome are affected, if candidate $i$ has some ability to move his platform from $x_{i}$. Rather than completely endogenizing candidate position, which would result in significant analytical challenges, we use a simplistic approach that nevertheless provides us with important insights. In particular, we suppose that an unforeseen opportunity arises for 
candidates to change their policy positions after the news about a candidate has been revealed. The question is whether such policy changes may affect the electoral outcome.

First, consider a case like the 2000 Presidential elections, where Proposition 6 predicts significant crossover voting. In such a scenario, a shift in platform $x_{i}$ immediately impacts vote share. In particular, emphasizing policy positions that move the candidate close to the center are advantageous. As Brownstein comments, ${ }^{13}$ "In the past few months, presumptive Republican nominee George W. Bush appears to have been reading from the Democratic Leadership Council playbook more closely than Gore. On a series of major issues, Bush has embraced the exact position taken by the DLC and its congressional allies." For example, a key part of Bush's 2000 platform was education, which is traditionally considered a Democratic issue. In fact, the 2000 exit polls reveal that, of the voters who indicated that education was the issue that mattered most, 52\% voted for Gore versus 44\% for Bush. In contrast, in the 1996 exit polls, $78 \%$ of these voters supported Clinton, and only $16 \%$ voted for Dole. This suggests that Bush's move to the center, by adopting a traditionally Democratic issue, successfully induced some voters to cross over.

Now consider a case like the 2004 Presidential elections in the context of Propositions 4 or 5. As explained above, all citizens $\theta>0$ believe that, if the conservative candidate is elected, their net-benefit is strictly bounded away from zero. The same is true for supporters of the liberal candidate. Thus, small, and possibly even larger, platform changes will not affect vote shares. Hence, attempts to adapt a campaign message to win over moderates are likely to fail. Rather, when all voters hold strong electoral views, devoting resources to increasing turnout of core supporters may be decisive. In fact, most political commentators attributed the Republican win in 2004 to their superior voter mobilization effort.

In a comment written two days before the 2004 elections, Suellentrop (2004) writes: "The secret of Bill Clinton's campaigns and of George W. Bush's election in 2000 was the much-maligned politics of small differences: Find the smallest possible majority (well, of electoral votes, for both men) that gets you to the White House. In political science, something called the median voter theorem dictates that in a two-party system, both parties will rush to the center looking for that lone voter - the median voter - who has 50.1 percent of the public to the right (or left) of him. Win that person's vote, and you've won the election." In contrast, Suellentrop's expectation for the 2004 election was that Bush's political strategist Karl Rove made a fatal mistake. "Bush's campaign - and his presidency — have appealed almost entirely to the base of the Republican Party... However, the early indications are that Rove's repudiation of centrist politics will backfire. Rove has tried to use the Bush campaign to disprove the politics of the median voter. It was as big a gamble as any of the big bets President Bush has placed over the past four years." It appears that Rove got it right this time too.

In summary, our model predicts that the incentive for political moderation is minimal when there is significant negative news about both candidates. Rather, what matters here is turning out core supporters, and moderation may also not be helpful for this purpose. In contrast, if there is little negative news about both candidates, then policies matter primarily, so that appealing to the median voter is the winning strategy.

\footnotetext{
${ }^{13}$ Los Angeles Times, April 17, 2000.
} 


\subsection{Increased Media Competition and Electoral Effects}

Now suppose that competition in the media market increases because of deregulation or changes in information technology resulting in lower fixed costs. Interestingly, increased competition can be either beneficial or harmful. In particular, if competition increases in a setting where media are biased, then unbiased news may provide a way for a new entrant to differentiate itself. That is, we get a constellation with biased outlets on the left, biased outlets on the right and an unbiased outlet for the middle. Again, an ex-post inefficient candidate choice can occur if voter $\tau$ listens to a biased outlet, i.e., $\tau>\left|\frac{\beta}{\alpha}\right|$. However, since moderates listen to unbiased news, the probability of a mistake decreases.

Increased competition can also have a detrimental effect on media bias. In particular, suppose we start with an electorate that is just not sufficiently polarized to make media bias optimal, and a third outlet enters the market. This outlet may find it in its interest to distinguish itself by offering biased news, rather than unbiased reporting. For example, if the outlet reports with a conservative slant, it will attract all listeners $\theta>\frac{\beta}{\alpha}$, while, with unbiased reporting, it does not distinguish itself from the other outlets. This, in turn, may induce an existing outlet to slant its news to the left. As Posner observed, "The rise of the conservative Fox News Channel caused CNN to shift to the left. CNN was going to lose many of its conservative listeners anyway, so it made sense to increase its appeal to its remaining viewers, by catering more assiduously to their political preferences."

In summary, increased media entry can either increase or decrease electoral mistakes. If a society is not very polarized and media competition is limited, then reporting will be unbiased, and no mistakes occur. If competition is increased, then it may be optimal for some outlets to be biased, and the wrong candidate may get elected. In contrast, if we start with a very polarized society then initially all outlets are biased. If competition is increased, then we would see the reverse of Posner's argument, i.e., it is optimal for some media outlet to cater to the political center by providing unbiased news. This, in turn, will lower the probability of electoral mistakes.

\section{Concluding Remarks}

In this paper, we provide an integrated model of media bias and its consequences for information aggregation in elections. In our model, partisan preferences for biased news may make it optimal for news media to pick sides and bias their reporting in a way that favors one candidate over his competitor. If media bias occurs, listeners to the liberal or conservative news outlet are incompletely informed about facts that are unfavorable for "their" candidate. Even if citizens are completely rational and take media bias into account, they cannot recover all of the missing information, which can lead to the election of the wrong candidate.

Polarization of the electorate makes it more profitable for media to provide biased broadcasts that appeal to more partisan audiences. Thus, in a more polarized a society, more voters receive their news from biased sources, which implies that not only the location of the median voter, but also the political polarization of society affects electoral outcomes.

We characterize the types of electoral mistakes that can occur due to media bias, depending on the nature of news available about candidates. For example, if both candidates are plagued by scandals (and this is the 
only significant information), then liberals hear about the conservative candidate's scandals and vice versa. As a result, liberals have a strong preference for the liberal candidate and conservatives for the conservative candidate. From an efficiency perspective, there is too much voting along party lines, and marginal changes of news or policy moderation by the candidates do not win votes. In contrast, if there is less extreme news about both candidates, then moderates have weak preferences, and there can be too much cross-over voting from an efficiency point of view. In this case, both marginal changes of news and policy moderation affect vote shares.

The fundamental reason for the inefficiency in electoral outcomes is that voters choose to listen to biased media. This effect is likely to be quite stable, even though the population as a whole would be much better off if media reported unbiased news. In principle, voters could become completely informed even with two biased media, by listening to both. However, few voters are likely to take advantage of this opportunity because of a fundamental positive externality problem: Each voter has only an infinitesimal chance of being pivotal and, even if he becomes informed and is pivotal, he receives only a very small fraction of the social benefits. The standard economic response to a positive externality is likely to fail, because a subsidy to news outlets for providing unbiased reporting may be difficult to implement. The best option for society may therefore be to foster a culture in which citizen appreciate learning about both sides of a political debate.

We conclude by discussing two important issues concerning the model's robustness. First, unless both media provide unbiased news, each outlet gets an interval of political preference types as listeners. For example, if an outlet provides news biased to the right, then there is a cutoff such that all citizens with political preferences to the right of that cutoff listen to this outlet, but no one else does. In practice, listener separation is less extreme. For example, some people may like to be informed about the opposing point of view on an issue, or may have idiosyncratic preferences for a particular outlet, unrelated to their political preferences. In this case, a right-biased outlet will not have an exclusively, just a predominantly, conservative audience. How does this change our results?

Consider, for example, Case 1 of Proposition 4. Those liberals who listen to the conservative outlet are now informed about the liberal candidate's weakness, instead of the conservative candidate's weakness. Consequently, some moderates among those differently-informed liberals cross over to vote for the conservative candidate. The same applies to conservatives who listen to the liberal outlet. In Case 1 of Proposition 4, the liberal candidate's net valence exceeds the conservative's, more liberally-informed conservatives cross over than do conservatively-informed liberals. Hence, the probability of a mistake is reduced, albeit only slightly, since cross-over of heterodox partisans occurs in both directions and so the net flow may be small. Thus, our results remain qualitatively unaffected, as long as our assumption that citizens prefer confirmatory news holds for a sufficiently large share of the population.

Second, our model assumes a symmetric distribution of $\theta$. This assumption is largely for technical convenience, and it is straightforward, albeit tedious to extend our analysis to asymmetric distributions. Moreover, Propositions 4 to 6 characterize electoral mistakes, given a particular realization of $\tau$. Some of these mistakes occur when $|\tau|$ is large, indicating that these mistakes are even more likely in a society where the expected median voter is a partisan. For example, in a state like Utah where the median voter $\tau$ is conservative, the liberal candidate could only win if the electorate learns very bad news about the conservative candidate. Moreover, if a large majority of citizens is quite conservative, then it is very attractive for media 
to adopt a conservative bias, so that the negative news about the conservative candidate may not reach the median voter. As a consequence, in a society where the expected median voter is a partisan, media bias may matter even more than in our symmetric environment. 


\section{Appendix}

In this Appendix, we normalize the expected net positive news for the left and the right candidate (if everything is reported) to 1 (i.e., $E_{Y}\left[Y_{R}^{+}+Y_{L}^{-}\right]=E\left[Y_{L}^{+}+Y_{R}^{-}\right]=1$ ). This economizes on notation and is without loss of generality, because we can adjust the parameters $\alpha, \beta, \gamma$ of the utility function accordingly.

Let $s_{i, L}$ and $s_{i, R}$ be the net expected news reported by media outlet $i$ about candidates $L$ and $R$, respectively. That is, $s_{i, L}$ equals the expected value of the positive news that is reported on candidate $L$ plus the negative news about candidate $R$. Formally, if we denote the $\ell$ th component of $\zeta_{i}$ by $\zeta_{i, \ell}$ then $s_{i, L}=E\left[\zeta_{i, 1}(Y) Y_{L}^{+}+\zeta_{i, 4}(Y) Y_{R}^{-}\right]$and $s_{i, R}=E\left[\zeta_{i, 2}(Y) Y_{L}^{-}+\zeta_{i, 3}(Y) Y_{R}^{+}\right]$. Note that $s_{i, k}$ can be chosen by media outlet $i$ to be any number between 0 and 1 (given our normalization of $E\left[Y_{L}^{+}\right]+E\left[Y_{R}^{-}\right]$or $E\left[Y_{R}^{+}\right]+E\left[Y_{L}^{-}\right]$), respectively, by an appropriate choice of $\zeta_{i}$.

Proof of Lemma 1. See text.

Lemma 3 Suppose media outlet $i$ and $j$ 's strategies are given by $s_{L, i}=s_{L, j}=1$. Then $s_{R, i}, s_{R, j} \in\{0,1\}$, i.e., both outlets are unbiased or maximally biased.

Proof of Lemma 3. First suppose that $s_{R, i} \neq s_{R, j}$. Then without loss of generality we can assume that $s_{R, i}<s_{R, j}$. Then citizen $\hat{\theta}$ who is indifferent between the two outlets would have the same listening time. (7) therefore implies that $\hat{\theta}$ is the solution to $\alpha \hat{\theta}\left(s_{R, j}-1\right)+\beta\left(1+s_{R, j}\right)=\alpha \hat{\theta}\left(s_{R, i}-1\right)+\beta\left(1+s_{R, i}\right)$. Solving this equation yields $\hat{\theta}=-\beta / \alpha$. Moreover, since $s_{R, i}<s_{R, j}$ (i.e., outlet $i$ reports less positive net news about the conservative candidate) all $\theta<\hat{\theta}$ listen to outlet $i$, while all $\theta>\hat{\theta}$ listen to $j$. Because $\hat{\theta}$ does not vary with $s_{R, i}$, it is optimal for outlet $i$ to set $s_{R_{i}}=0$, as it increases the listening time of all citizens $\theta<\hat{\theta}$. Similarly, it follows that outlet $j$ should choose $s_{R, j}=1$.

Now suppose by way of contradiction that $0<s_{R, i}=s_{R, j}<1$. Without loss of generality assume that $j$ 's expected profits $E\left[\pi_{j}\right]$ are less than or equal to $i$ 's. If outlet $j$ increases $s_{R, j}$ to 1 then we can again conclude that all citizens $\theta>-\frac{\beta}{\alpha}$ listen to outlet $j$. Otherwise, if $s_{R, j}$ is reduced to 0 , all citizens $\theta<-\frac{\beta}{\alpha}$ listen to $j$. Because $j$ 's profits are maximized in equilibrium,

$$
\begin{aligned}
& E\left[\pi_{j}\right] \geq \int_{-\frac{\beta}{\alpha}}^{\infty}[\gamma+2 \beta] d H(\theta)>\int_{-\frac{\beta}{\alpha}}^{\infty}\left[\gamma+\alpha \theta\left(s_{R, j}-1\right)+\beta\left(1+s_{R, j}\right)\right] d H(\theta) ; \\
& E\left[\pi_{j}\right] \geq \int_{-\infty}^{-\frac{\beta}{\alpha}}[\gamma+\alpha \theta+\beta] d H(\theta)>\int_{-\infty}^{-\frac{\beta}{\alpha}}\left[\gamma+\alpha \theta\left(s_{R, j}-1\right)+\beta\left(1+s_{R, j}\right)\right] d H(\theta) .
\end{aligned}
$$

Adding (10) and (11) yields

$$
2 E\left[\pi_{j}\right]>\int_{-\infty}^{\infty}\left[\gamma+\alpha \theta\left(s_{R, j}-1\right)+\beta\left(1+s_{R, j}\right)\right] d H(\theta)=E\left[\pi_{i}\right]+E\left[\pi_{j}\right],
$$

which contradicts the assumption that outlet $j$ 's profit do not exceed those of outlet $i$. This contradiction proves the Lemma.

Lemma 4 Suppose media outlet $i$ and $j$ 's strategies are given by $s_{L, i}=1, s_{R, i}=x$, and $s_{R, j}=1, s_{L, j}=y$. Then Condition 1 implies that the media outlet's payoff is convex in $x$. 
Proof of Lemma 4. Without loss of generality consider the case where the set of listeners is $S_{i}=(-\infty, \hat{\theta}]$. Then $\hat{\theta}$ is determined by $\alpha \hat{\theta}(x-1)+\beta(1+x)=\alpha \hat{\theta}(1-y)+\beta(1+y)$, so that

$$
\hat{\theta}=\frac{\beta}{\alpha} \frac{x-y}{(2-x-y)} .
$$

The derivatives of (12) are

$$
\frac{\partial \hat{\theta}}{\partial x}=\frac{\beta}{\alpha} \frac{2(1-y)}{(2-x-y)^{2}}, \text { and } \frac{\partial^{2} \hat{\theta}}{\partial x^{2}}=\frac{2}{2-x-y} \frac{\partial \hat{\theta}}{\partial x} .
$$

Media outlet $i$ chooses $x$ to maximize its aggregate listening time:

$$
\int_{-\infty}^{\hat{\theta}}[\gamma+\alpha \theta(x-1)+\beta(1+x)] h(\theta) d \theta
$$

Taking the derivative with respect to $x$ yields

$$
\int_{-\infty}^{\hat{\theta}(x)}[\alpha \theta+\beta] h(\theta) d \theta+\frac{\partial \hat{\theta}}{\partial x}[\gamma+\alpha \hat{\theta}(x-1)+\beta(1+x)] h(\hat{\theta}) .
$$

Using (13), the second derivative is

$$
\begin{aligned}
& \frac{\beta}{\alpha} \frac{4(1-y)}{(2-x-y)^{2}}[\alpha \hat{\theta}+\beta] h(\hat{\theta})+\frac{\beta}{\alpha} \frac{4(1-y)}{(2-x-y)^{3}}[\gamma+\alpha \hat{\theta}(x-1)+\beta(1+x)] h(\hat{\theta}) \\
& +\left[\frac{\beta}{\alpha} \frac{2(1-y)}{(2-x-y)^{2}}\right]^{2} \alpha(x-1) h(\hat{\theta})+\left[\frac{\beta}{\alpha} \frac{2(1-y)}{(2-x-y)^{2}}\right]^{2}[\gamma+\alpha \hat{\theta}(x-1)+\beta(1+x)] h^{\prime}(\hat{\theta}) .
\end{aligned}
$$

After substituting $\hat{\theta}$, the sum of the first and third term is

$$
\frac{\beta^{2}}{\alpha} \frac{4(1-y)^{2} h(\hat{\theta})}{(2-x-y)^{3}}(1+x)>0 .
$$

The sum of the remaining two terms is

$$
\frac{\beta}{\alpha} \frac{4(1-y)}{(2-x-y)^{3}}[\gamma+\alpha \hat{\theta}(x-1)+\beta(1+x)]\left[h(\hat{\theta})+\frac{\beta(1-y)}{\alpha(2-x-y)} h^{\prime}(\theta)\right] .
$$

The first term in square brackets is the listening time of the marginal viewer (and hence positive). Further, $(1-y) /(2-x-y)<1$. Thus, (1) guarantees that the second term in square brackets is also nonnegative. Hence, the profit function is convex.

Proof of Proposition 1. The result follows immediately from Lemma 3 and Lemma 4. In particular, the convexity of payoffs implies that the optimum is at a boundary.

Lemma 5 Suppose there are two media outlets, $i=1,2$. Then there exist exactly three types of equilibria.

1. An equilibrium featuring media outlets with opposing biases exists if and only if

$$
\frac{1}{2}\left[\gamma+\left(\alpha E_{\Theta}[\Theta \mid \Theta \geq 0]+\beta\right) E\left[Y_{R}^{+}+Y_{L}^{-}\right]\right] \geq H\left(\frac{\beta}{\alpha}\right)\left[\gamma+2 \beta E\left[Y_{R}^{+}+Y_{L}^{-}\right]\right] .
$$


2. An equilibrium with two unbiased outlets exists if and only if

$$
\frac{1}{2}\left[\gamma+2 \beta E\left[Y_{R}^{+}+Y_{L}^{-}\right]\right] \geq\left(1-H\left(\frac{\beta}{\alpha}\right)\right)\left[\gamma+\left(\alpha E_{\Theta}\left[\Theta \mid \Theta \geq \frac{\beta}{\alpha}\right]+\beta E\left[Y_{R}^{+}+Y_{L}^{-}\right]\right)\right] .
$$

3. An equilibrium with one biased and one unbiased media outlet exists if and only if

$$
H\left(\frac{\beta}{\alpha}\right)\left[\gamma+2 \beta E\left[Y_{R}^{+}+Y_{L}^{-}\right]\right] \geq \frac{1}{2}\left[\gamma+\left(\alpha E_{\Theta}[\Theta \mid \Theta \geq 0]+\beta\right) E\left[Y_{R}^{+}+Y_{L}^{-}\right]\right] .
$$

Proof of Lemma 5. First, we show that both media outlet are not biased to the left. If both are biased to the left then the set of all listeners must be an interval, $(-\infty, \hat{\theta}]$. Without loss of generality suppose that media 1's expected profit $E\left[\pi^{1}\right]$ are less or equal to those of media 2 and hence

$$
E\left[\pi^{1}\right] \leq 0.5 H(\hat{\theta})\left[\gamma+\left(\alpha E_{\Theta}[-\Theta \mid \Theta<\hat{\theta}]+\beta\right) 2 \bar{Y}\right] .
$$

Now suppose that outlet 1 provides news that is biased to the right. Then the set of listeners is $[0, \infty)$, so that profits are

$$
E\left[\tilde{\pi}^{1}\right]=H(0)\left[\gamma+\left(\alpha E_{\Theta}[\Theta \mid \Theta \geq 0]+\beta\right) 2 \bar{Y}\right] .
$$

Note that $0.5 \geq 0.5 H(\hat{\theta})$, with a strict inequality if $\hat{\theta}$ is in the support of $H$. Furthermore, $E_{\Theta}[\Theta \mid \Theta \geq 0] \geq$ $E_{\Theta}[-\Theta \mid \Theta<\hat{\theta}]$, with a strict inequality for $\hat{\theta}>0$. Thus, (21) and (22) imply that $E\left[\tilde{\pi}^{1}\right]>E\left[\pi^{1}\right]$, i.e., news outlet 1 has profitable deviation, a contradiction. Similarly, both outlets cannot be biased to the right. As a consequence, only the three cases listed in the Proposition remain.

Now suppose that both outlets have opposing biases. In equilibrium it must be the case that no outlet wants to deviate by offering unbiased news. Because of symmetry it is sufficient to only consider deviations by the news outlet that is biased to the left. In equilibrium, this news outlet's profit is given by the lefthand side of (18). This follows by taking the expectation over consumer demand given by (5). Note that $H(0)$ is the mass of the set of all listeners $\theta<0$, and $E_{\Theta}[\Theta \mid \Theta \leq 0]=-E_{\Theta}[\Theta \mid \Theta \geq 0]$ is the average listener to the news outlet. If the news outlet decides to offer unbiased news, then the set of listeners is $(-\infty, \beta / \alpha]$. Moreover, $E_{Y}\left[y_{R}^{+}+y_{L}^{-}-y_{R}^{-}-y_{L}^{+}\right]=0$, because the expected value of all news items are equal. Thus, the payoff from offering biased news is given by the right-hand side of (18), which indicates that (18) is necessary. The condition is also sufficient because becoming unbiased is the only possibly optimal deviation.

Next, suppose that both outlets are unbiased. Let $S_{i}, i=1,2$ be the set of listeners. Without loss of generality assume that the mass of $S_{1}$ (denoted by $P\left(S_{1}\right)$ ) is less or equal to that of $S_{2}$. Thus, $P\left(S_{1}\right) \leq 0.5$. The payoff of news outlet 1 is then $P\left(S_{1}\right)[\gamma+4 \beta \bar{Y}]$, since the coefficient of $\alpha$ disappears for the same reason as above. Now, suppose that the news outlet deviates to a right bias. Then its listeners are all citizens $\theta \geq \beta / \alpha$. The news outlet's payoff is therefore given by the right-hand side of (19). To have an equilibrium, $P\left(S_{1}\right)[\gamma+4 \beta \bar{Y}]$ must therefore be greater or equal to the right-hand side of (19). Because $P\left(S_{1}\right) \leq 0.5=H(0)$, it follows that (19) is necessary. Sufficiency follows by, for example, choosing $S_{1}=\{\theta<0\}$ and $S_{2}=\{\theta \geq 0\}$.

Now suppose that one outlet is biased and the other is unbiased. Suppose the biased news outlet deviates and becomes unbiased. Then the following is an equilibrium in the subgame: The original biased media 
outlet receives all listeners, and the deviating outlet receives no listeners. As a consequence, the deviation lowers profits. It is therefore sufficient to ensure that that the unbiased outlet does not deviate by becoming biased. This condition is given by (20) and the derivation mirrors that of the other constraints.

Proof of Proposition 2. If follows immediately that if (18) is violated then (20) must hold, and vice versa. Thus, an equilibrium with a biased and an unbiased media exists if no equilibrium with two biased media exists. The cutoff $\alpha_{1}$ is given by the value of $\alpha$ where (18) (or (20)) holds with equality, i.e.,

$$
H(0)\left[\gamma+\left(\alpha_{1} E_{\Theta}[\Theta \mid \Theta \geq 0]+\beta\right) 2 \bar{Y}\right]-H\left(\frac{\beta}{\alpha_{1}}\right)[\gamma+4 \beta \bar{Y}]=0 .
$$

Differentiating (23) with respect to $\alpha$ yields

$$
\begin{array}{r}
\alpha_{1}^{\prime}(\beta)\left[H(0) E_{\Theta}[\Theta \mid \Theta \geq 0] 2 \bar{Y}+\frac{\beta}{\alpha_{1}^{2}(\beta)} h\left(\frac{\beta}{\alpha}\right)[\gamma+4 \beta \bar{Y}]\right] \\
=\frac{1}{\alpha_{1}} h\left(\frac{\beta}{\alpha}\right)[\gamma+4 \beta \bar{Y}]+H\left(\frac{\beta}{\alpha}\right) 4 \bar{y}-H(0) 2 \bar{y}>0,
\end{array}
$$

because the coefficient of $\alpha_{1}^{\prime}(\beta)$ is strictly positive and because $H\left(\frac{\beta}{\alpha}\right) \geq H(0)$. Thus, $\alpha_{1}$ is strictly increasing in $\beta$. It follows immediately that a biased-biased equilibrium occurs if $\alpha>\alpha_{1}$ because the right-hand side of (18) is decreasing in $\alpha$, whereas the left-hand side is increasing in $\alpha$.

Next, we define $\alpha_{2}$ as the value of $\alpha$ where (19) holds with equality. The derivatives of

$$
H(0)[\gamma+4 \beta \bar{Y}]-\left(1-H\left(\frac{\beta}{\alpha}\right)\right)\left[\gamma+\left(\alpha E_{\Theta}\left[\Theta \mid \Theta \geq \frac{\beta}{\alpha}\right]+\beta\right) 2 \bar{y}\right]
$$

with respect to $\alpha$ and $\beta$ are given by

$$
\begin{aligned}
& \frac{\partial}{\partial \alpha}:-2 \bar{y} \int_{\beta / \alpha}^{\infty} \theta h(\theta) d \theta-\frac{\beta}{\alpha^{2}} h\left(\frac{\beta}{\alpha}\right) \gamma<0, \\
& \frac{\partial}{\partial \beta}: 4 \bar{y} H(0)-\left(1-H\left(\frac{\beta}{\alpha}\right)\right) 2 \bar{y}+\frac{1}{\alpha} h\left(\frac{\beta}{\alpha}\right)\left[\gamma+\left(\alpha E_{\Theta}\left[\Theta \mid \Theta \geq \frac{\beta}{\alpha}\right]+\beta\right) 2 \bar{y}\right]>0 .
\end{aligned}
$$

The sign for the second derivative follows because $\left(1-H\left(\frac{\beta}{\alpha}\right)\right) \leq H(0)$. Thus, $\alpha_{2}$ is strictly increasing in $\beta$ and an unbiased-unbiased equilibrium exists for all $\alpha \leq \alpha_{2}$.

It remains to prove that $\alpha_{2}<\alpha_{1}$. Suppose that $\alpha=\alpha_{2}$ so that (24) equals zero. It suffices show that

$$
H(0)\left[\gamma+\left(\alpha E_{\Theta}[\Theta \mid \Theta \geq 0]+\beta\right) 2 \bar{y}\right]-H\left(\frac{\beta}{\alpha}\right)[\gamma+4 \beta \bar{y}]<0
$$

Because (24) is zero, we can subtract the expression from (25) to get

$$
\begin{aligned}
& 2 \bar{y}\left[H(0) \alpha E_{\Theta}[\Theta \mid \Theta \geq 0]-\left(1-H\left(\frac{\beta}{\alpha}\right)\right) \alpha E_{\Theta}\left[\Theta \mid \Theta \geq \frac{\beta}{\alpha}\right]-\left(H\left(\frac{\beta}{\alpha}\right)-H(0)\right) \beta\right] \\
& \quad=2 \bar{y}\left[\alpha \int_{0}^{\infty} \theta h(\theta) d \theta-\alpha \int_{\beta / \alpha}^{\infty} \theta h(\theta) d \theta-\left(H\left(\frac{\beta}{\alpha}\right)-H(0)\right) \beta\right] \\
& \quad=2 \bar{y} \alpha\left[\int_{0}^{\beta / \alpha} \theta h(\theta) d \theta-\left(H\left(\frac{\beta}{\alpha}\right)-H(0)\right) \frac{\beta}{\alpha}\right] .
\end{aligned}
$$


To show that (26) is strictly negative it is therefore sufficient to prove that

$$
\psi(x)=\int_{0}^{x} \theta h(\theta) d \theta-(H(x)-H(0)) x<0,
$$

for $x>0$. Note that $\psi(0)=0$. Furthermore,

$$
\psi^{\prime}(x)=x h(x)-x h(x)-(H(x)-H(0))=-H(x)+H(0)<0,
$$

because $x>0$. Thus, $\psi(x)<0$, which implies that (26) is strictly negative and hence (18) is violated. Thus, $\alpha=\alpha_{2}>\alpha_{1}$.

Proof of Proposition 3. First consider equation (8). The left-hand side is independent of $H$ or $\hat{H}$. Because the distributions are symmetric, $1-H\left(\frac{\beta}{\alpha}\right)=H\left(-\frac{\beta}{\alpha}\right)$ and $1-\hat{H}\left(\frac{\beta}{\alpha}\right)=\hat{H}\left(-\frac{\beta}{\alpha}\right)$. Moreover,

$$
\begin{aligned}
\int_{-\infty}^{-\frac{\beta}{\alpha}} \theta h(\theta) d \theta & =\left.H(\theta) \theta\right|_{-\infty} ^{-\frac{\beta}{\alpha}}-\int_{-\infty}^{-\frac{\beta}{\alpha}} H(\theta) d \theta=-H\left(-\frac{\beta}{\alpha}\right) \frac{\beta}{\alpha}-\int_{-\infty}^{-\frac{\beta}{\alpha}} H(\theta) d \theta \\
& >-\hat{H}\left(-\frac{\beta}{\alpha}\right) \frac{\beta}{\alpha}-\int_{-\infty}^{-\frac{\beta}{\alpha}} \hat{H}(\theta) d \theta=\int_{-\infty}^{-\frac{\beta}{\alpha}} \theta \hat{h}(\theta) d \theta .
\end{aligned}
$$

Thus, $\int_{\frac{\beta}{\alpha}}^{\infty} \theta h(\theta) d \theta<\int_{\frac{\beta}{\alpha}}^{\infty} \theta \hat{h}(\theta) d \theta$. This, together with $\left(1-H\left(\frac{\beta}{\alpha}\right)\right)<\left(1-\hat{H}\left(\frac{\beta}{\alpha}\right)\right)$ imply that the righthand side of equation (8) is higher for $\hat{H}$ than for $H$. As a consequence, $\alpha_{1}$ is lower for $\hat{H}$. The proof for $\alpha_{2}$ is similar.

Proof of Lemma 2. Note that $\left(\tau-x_{i}\right)^{2}+\kappa q_{i} \geq\left(\tau-x_{j}\right)^{2}+\kappa q_{j}$ if and only if $\tau^{2}-2 \tau x_{i}+\kappa q_{i} \geq$ $\tau^{2}-2 \tau x_{j}+\kappa q_{j}$, because $x_{i}^{2}=x_{j}^{2}$. Since $f(\theta)$ is symmetric we get $\int\left(\theta-x_{L}\right)^{2} f(\theta) d \theta=\int\left(\theta-x_{R}\right)^{2} f(\theta) d \theta$. Thus, $-\int\left(\theta-x_{i}\right)^{2} f(\theta) d \theta+\tau^{2}-2 \tau x_{i}+\kappa q_{i} \geq-\int\left(\theta-x_{j}\right)^{2} f(\theta) d \theta+\tau^{2}-2 \tau x_{j}+\kappa q_{j}$, which is equivalent to $-\int\left(\tau+\theta-x_{i}\right)^{2} f(\theta) d \theta+\kappa q_{i} \geq-\int\left(\tau+\theta-x_{j}\right)^{2} f(\theta) d \theta+\kappa q_{j}$, i.e., the selection of candidate $i$ is efficient.

Proof of Proposition 4. If both outlets are unbiased, then $\tau$ 's vote is decisive and therefore his most preferred candidate is elected. Lemma 2 implies that the choice is efficient.

Now suppose there are two biased outlets. Consider a liberal citizen $\theta>0$. Then $\theta$ only receives the net news about the liberal candidate. He assigns the average net news realization $\bar{z}$ to the conservative candidate. Because $\left(\theta-x_{L}\right)^{2}+\kappa\left(z_{L}-\bar{z}\right)>\left(\theta-x_{R}\right)^{2}$, we get $\left(\theta-x_{L}\right)^{2}+\kappa E_{\theta}\left[q_{L}\right]>\left(\theta-x_{R}\right)^{2}+\kappa E_{\theta}\left[q_{R}\right]$, where $E_{\theta}[\cdot]$ is the expectation of citizen $\theta$ conditional on the information received from the left-biased news outlet. Because $z_{L}>\bar{z}$ this inequality is strict even when $\theta=0$, i.e., liberals believe to be significantly better with the liberal candidate. Similarly, $z_{R}>\bar{z}$ implies that conservatives believe to be significantly better with conservative candidate. Thus, $\tau$ 's vote is again decisive: If $\tau>0$ then the liberal candidate wins, otherwise, if $\tau<0$ the conservative candidate is elected.

If $\tau<0$ no electoral mistakes occur, because $z_{L}>z_{R}$. Now suppose that $\tau<0$. It follows immediately that $\tau$ prefers candidate $L$ if and only if $\tau \geq \frac{\kappa\left(z_{L}-z_{R}\right)}{4 x_{R}}$. Thus, Lemma 2 implies that a mistake occurs if and only if $0<\tau<\frac{\kappa\left(z_{L}-z_{R}\right)}{4 x_{R}}$. 
If the outlet on the right is biased and the other outlet is unbiased, then $\tau$ can only choose the wrong candidate if he listens to the biased outlet, i.e., if $\tau>\beta / \alpha$ and if $\tau$ would prefer candidate $L$ if he knew $L$ 's valence $z_{L}$, i.e., if $\tau<\frac{\kappa\left(z_{L}-z_{R}\right)}{4 x_{R}}$. If the outlet on the left is biased, then no mistake can occur.

Proof of Proposition 5. Again, if both outlets are unbiased, then the electoral choice is efficient. Now, suppose both outlets are biased. As in the proof of Proposition $4, z_{L}>\bar{z}$ implies that liberals $\theta<0$ believe to be significantly better off with the liberal candidate. Now, however, conservatives observe net news $z_{R}<\bar{z}$ about their candidate, and thus expect a better net news $\bar{z}$ about the liberal candidate. As a consequence, some conservatives vote for the liberal candidate. Straightforward algebra reveals that this is true for all conservatives $0 \leq \theta<\frac{\kappa\left(\bar{z}-z_{R}\right)}{4 x_{R}}$. However, as the liberal candidate's net news $z_{L}>\bar{z}$ too few conservatives cross over. In particular, if a conservative knew $z_{L}$, then he would vote for the liberal candidate if and only if $\theta<\frac{\kappa\left(z_{L}-z_{R}\right)}{4 x_{R}}$. Thus, an electoral mistake occurs if and only if $\frac{\kappa\left(\bar{z}-z_{R}\right)}{4 x_{R}}<\tau<\frac{\kappa\left(z_{L}-z_{R}\right)}{4 x_{R}}$.

Finally, suppose there is a biased and an unbiased outlet. If the biased outlet is biased to the left then all liberals will correctly vote for the liberal candidates. Thus, mistakes could only occur if the biased outlet is biased to the right. Similar to above it follows that $\frac{\kappa\left(\bar{z}-z_{R}\right)}{4 x_{R}}<\tau<\frac{\kappa\left(z_{L}-z_{R}\right)}{4 x_{R}}$ must hold for a mistake to occur. In addition, $\tau$ must listen to the biased outlet, i.e., $\tau>\frac{\beta}{\alpha}$.

Proof of Proposition 6. Again, if both outlets are unbiased, then the electoral choice is efficient. Now suppose both outlets are biased. As in the proof of Proposition 5 it follows that all citizens $0<\theta<\frac{\kappa\left(\bar{z}-z_{R}\right)}{4 x_{R}}$ vote for candidate $L$. Similarly, $z_{L}<\bar{z}$ implies that all citizens $0>\theta>-\frac{\kappa\left(\bar{z}-z_{L}\right)}{4 x_{R}}$ cross over and vote for candidate $R$. As a result, citizen $\theta$ votes for candidate $L$ if and only if $\theta<-\frac{\kappa\left(\bar{z}-z_{L}\right)}{4 x_{R}}$ or $0<\theta<\frac{\kappa\left(\bar{z}-z_{R}\right)}{4 x_{R}}$. Thus, given a realization of $\tau$, candidate $L$ wins if $F\left(-\frac{\kappa\left(\bar{z}-z_{L}\right)}{4 x_{R}}-\tau\right)+F\left(\frac{\kappa\left(\bar{z}-z_{R}\right)}{4 x_{R}}-\tau\right)-F(-\tau)>0.5$. Basic algebra reveals that citizen $\tau$ prefers candidate $L$ if $\tau<\frac{\kappa\left(z_{L}-z_{R}\right)}{4 x_{R}}$. Thus, Lemma 2 implies an ex-post inefficiency if $\tau>\frac{\kappa\left(z_{L}-z_{R}\right)}{4 x_{R}}$. Finally, note that $\tau>\frac{\kappa\left(\bar{z}-z_{R}\right)}{4 x_{R}}$ cannot hold. Otherwise, the symmetry of $f(\cdot)$ implies that candidate $R$ wins. Thus, $\frac{\kappa\left(z_{L}-z_{R}\right)}{4 x_{R}}<\tau<\frac{\kappa\left(\bar{z}-z_{R}\right)}{4 x_{R}}$.

Now suppose that the conservative candidate wins, i.e., $F\left(-\frac{\kappa\left(\bar{z}-z_{L}\right)}{4 x_{R}}-\tau\right)+F\left(\frac{\kappa\left(\bar{z}-z_{R}\right)}{4 x_{R}}-\tau\right)-F(-\tau)<$ 0.5. Citizen $\tau$ would prefer candidate $L$ if $\tau<\frac{\kappa\left(z_{L}-z_{R}\right)}{4 x_{R}}$. Note that we must have $\tau>-\frac{\kappa\left(\bar{z}-z_{L}\right)}{4 x_{R}}$, else the symmetry of $f(\cdot)$ implies that candidate $L$ wins. This provides the second condition of the Proposition.

We now consider the case of an unbiased and a right-biased outlet. The argument is similar to the first part of the proof, except that inefficient choices can now only occur if $\tau$ listens to a biased outlet, i.e., $\tau>\frac{\beta}{\alpha}$, and citizen $\tau$ is better off with candidate $R$, i.e., $\tau>\frac{\kappa\left(z_{L}-z_{R}\right)}{4 x_{R}}$, but candidate $L$ is elected.

First, suppose that $\frac{\beta}{\alpha}<\frac{\kappa\left(z_{L}-z_{R}\right)}{4 x_{R}}$. Then all citizens $\theta<\frac{\beta}{\alpha}$ vote for candidate $L$. Similarly, $\theta<\frac{\kappa\left(\bar{z}-z_{R}\right)}{4 x_{R}}$ who listen to the biased outlet, i.e., $\theta \geq \frac{\beta}{\alpha}$ also vote for $L$. Thus, the symmetry of the distribution implies that candidate $L$ is elected if $\frac{\beta}{\alpha}<\tau<\frac{\kappa\left(\bar{z}-z_{R}\right)}{4 x_{R}}$, but $\tau$ is better off with candidate $R$ if $\tau>\frac{\kappa\left(z_{L}-z_{R}\right)}{4 x_{R}}$.

Next, suppose that $\frac{\beta}{\alpha}>\frac{\kappa\left(z_{L}-z_{R}\right)}{4 x_{R}}$. Then candidate $L$ is elected if $F\left(\frac{\kappa\left(z_{L}-z_{R}\right)}{4 x_{R}}-\tau\right)+F\left(\frac{\kappa\left(\bar{z}-z_{R}\right)}{4 x_{R}}-\tau\right)-$ $F\left(\frac{\beta}{\alpha}-\tau\right)>0.5$. Citizen $\tau$ would be better off with candidate $R$ if $\frac{\beta}{\alpha}<\frac{\kappa\left(z_{L}-z_{R}\right)}{4 x_{R}}<\tau<\frac{\kappa\left(\bar{z}-z_{L}\right)}{4 x_{R}}$, resulting in an ex-post inefficient electoral outcome. 
Finally, suppose there is a biased outlet to the left and an unbiased outlet. Inefficiencies can only occur if $\tau<\frac{\beta}{\alpha}$, so that the median voters listens to the biased outlet, and $\tau>-\frac{\kappa\left(\bar{z}-z_{L}\right)}{4 x_{R}}$ so that the median voter votes for candidate $R$. For candidate $R$ to be elected $F\left(\frac{\kappa\left(\bar{z}-z_{L}\right)}{4 x_{R}}-\tau\right)+F\left(\frac{\kappa\left(z_{L}-z_{R}\right)}{4 x_{R}}-\tau\right)-F\left(\frac{\beta}{\alpha}-\tau\right)<0.5$. 


\section{References}

Alterman, E. (2003). What liberal media?: The truth about bias and the news. New York, Basic Books.

Baron, D. (2004). Persistent media bias. Stanford GSB working paper \#1845.

Börgers, T. (2004). Costly voting. American Economic Review 94(1), 57-66.

Coulter, A. (2003). Slander: Liberal Lies about the American Right. New York, Three Rivers Press.

Della Vigna, S. and E. Kaplan (2005). The Fox News effect: Media bias and voting. Berkeley.

Downs, A. (1957). An Economic Theory of Democracy. New York: Harper.

Feddersen, T. and W. Pesendorfer (1996). The swing voter's curse. American Economic Review 86, 408424.

Feddersen, T. and W. Pesendorfer (1997). Voting behavior and information aggregation in elections with private information. Econometrica 65, 1029-1058.

Fiorina, M. P., S. J. Abrams, and J. C. Pope (2004). Culture War? The Myth of a Polarized America. Longman.

Franken, A. (2003). Lies and the lying liars who tell them: A fair and balanced look at the right. New York, EP Dutton.

Gentzkow, M. and J. Shapiro (2005). Media bias and reputation. mimeo, Chicago GSB.

Goldberg, B. (2003). Bias: A CBS insider exposes how the media distort the news. Washington, D.C., Regnery Pub.

Groseclose, T. and J. Milyo (2005). A measure of media bias. Quarterly Journal of Economics, forthcoming.

Krasa, S. and M. K. Polborn (2005). Is mandatory voting better than voluntary voting? mimeo, University of Illinois.

Ledyard, J. (1984). Pure theory of two-candidate competition. Public Choice 44, 7-41.

Martinelli, C. (2004). Would rational voters acquire costly information? forthcoming Journal of Economic Theory.

Mullainathan, S. and A. Shleifer (2005). The market for news. American Economic Review, forthcoming.

Osborne, M. (1995). Spatial models of political competition under plurality rule: A survey of some explanations of the number of candidates and the positions they take. Canadian Journal of Economics 27, 261-301.

Polborn, M. K. and D. Yi (2006). Positive and negative campaigning. forthcoming Quarterly Journal of Political Science.

Posner, R. A. (2005). Bad news. New York Times, July 31, 2005.

Suellentrop, C. (2004). The vanishing nonvoter. Slate, http://www.slate.com/id/2108924/.

Wittman, D. (1989). Why democracies produce efficient results. Journal of Political Economy 97(6), 1395-1424.

Wittman, D. (2005). Reply to Caplan: On the methodology of testing voter irrationality. Econ Journal Watch 2, 22-31. 